\title{
Awareness of Sexual Trafficking and Associated Factors Among Youth Females in Debre Birhan Town, North Shewa, Ethiopia 2019: Community Based Cross-sectional Study
}

\author{
Natnael Atnafu \\ Lecturer in the Department of Midwifery, College of Health Science and Medicine, Wolaita Sodo University, \\ Wolaita Sodo, Ethiopia \\ Awoke Elefachew \\ Lecturer in the Department of Nursing, Colleague of health science, DebreBerhan Health Science Colleague, \\ DebreBerhan, Ethiopia
}

\begin{abstract}
Background: sexual trafficking is a major issue affecting both developing and developed countries. Therefore, this study aimed to assess sexual trafficking and associated factors among female youths in Debre Berhan town, North Shewa, Ethiopia

Methods: - Community based cross-sectional study was conducted by using systematic random sampling method of data collection from February 05 to April 10, 2019 from a total of 582 youth females.

Result: Among the total of 582 study participants $300(52 \%)$ of the participants had awareness about sexual trafficking. Mother's educational status; elementary [AOR=2.068, 95\% CI(1.079-3.963)] and secondary[AOR=3.446, 95\% CI(1.298-9.154)], parents' occupational status ;governmental worker [AOR=2.2, $95 \% \mathrm{CI}(1.02-4.747)]$, participants occupational status $[\mathrm{AOR}=6.203,95 \% \mathrm{CI}(1.099-35.005)]$, having television at home $[\mathrm{AOR}=2.083,95 \% \mathrm{CI}(1.305-3.326)]$ and taking training on gender issues [AOR=3.887,95\% CI: (2.5915.832)] were independent predictors risk factors for awareness of sexual trafficking. Conclusion: In this study, sexual trafficking awareness among female youth was low. Mother education status, parents' occupation, participant's job, having television in home and taking training on gender issues were significantly associated with awareness of sexual trafficking. Therefore, accessibilities of education and information through the community have to be taken as strategy for enhancing awareness of sexual trafficking among youth.
\end{abstract}

Keywords: Awareness, Sexual trafficking, Youth females

DOI: $10.7176 / \mathrm{JHMN} / 72-02$

Publication date:March $31^{\text {st }} 2020$

\section{INTRODUCTION}

Background: Sexual trafficking is a contemporary public health issue of both developed and developing countries that violates human rights and has been described as a modern form of slavery [1]. The United Nation defines sex trafficking as "the recruitment, transportation, transfer, harboring, or receipt of persons, by means of the threat or use of force or other forms of coercion, abduction, fraud, deception, abuse of power or a position of vulnerability" for the purposes of sexual exploitation and for economic and other personal gains [2].

According to the United Nation Office on Drugs and Crime report, the numbers of trafficked women have increased in Sub-Saharan Africa including Ethiopia due to low awareness [3]. International Labor Organization estimated that there are 4.5 million victims of forced sexual exploitation worldwide; $98 \%$ of whom are estimated to be women and girls. The causes of unawareness of sexual trafficking are its hidden nature, Access of source of information, socio demographic condition of the families and the participant, lack of training on violence[4]. In Ethiopia, sexual trafficking mostly takes the form of transporting migrants by fraud, deception and different forms of coercion and it causes a number of serious problems, turning the hope of many young girls to tragedy [5]. The external sexual trafficking is occurred on Ethiopian young females out of Ethiopia. According to U.S. Department of State report, in the first half of 2012 alone, over 160,000 migrants migrated regularly to Saudi Arabia to work in the domestic sector, using the services of Private Employment Agencies [6]. The US Department of State reports that Ministry of Labor and Social Affairs (MOLSA) even estimates that the 200,000 regular labour migrants in 2012 represent just 30 to $40 \%$ of all Ethiopians migrating to the Middle East, implicating that the remaining $60 \%$ to $70 \%$ are either sexually trafficked or smuggled with the facilitation of illegal brokers[7]. The above report also shows that of the migrants of the year 2012 , more than $85 \%$ are young female students who either dropped or quitted schools at primary or secondary level. Similarly, the ILO report of 2013 on migrant workers indicated that, one of the largest current international migration flows is Ethiopian women and girls migrating to the Middle East as domestic workers, which also often occurs through trafficking. In recent times the number of sexually trafficked Ethiopian women to the Middle East has dramatically increased [8]. 
The consequence of sexual trafficking is multifold including the physical, psychological, social, economic and political problems. Different studies also reported that sex trafficking has high negative impact on the physical, mental, social and psychological wellbeing of women and girls [9-12].

Many young girls away from their schools and homes in poor, rural areas with the promise of jobs and other opportunities in cities like Addis Ababa, Ethiopia, but they are exposed for sexual trafficking by influencing their employer. Many victim of sexual trafficking ended up being exploited as maids and sex workers in their country Ethiopia [9].

There are also some studies conducted by individual researchers on human trafficking in Ethiopia [1214].Most of these studies are highly concerned on the investigation of the challenges, prospects, and different kinds of right violations that Ethiopian domestic workers experience in the Arab Middle East. However, there is no enough research on young females' awareness about sex trafficking in the study area as well as in Ethiopia. So, reliable evidence on awareness of sex trafficking at grass root level is important to formulate evidence based approaches for effective preventative interventions against sexual trafficking. Therefore, this study is designed to assess awareness of sex trafficking and associated factors among youth females in Debre Birhan town, NorthShewa, Ethiopia.

\section{Main text}

Methods

Study area, design and period

Institutional based cross-sectional study was conducted from February 05 to April 10, 2019 among female youths in Debra Birhan town, North Shewa, Ethiopia. The town is found $120 \mathrm{~km}$ away from the capital city of Addis Ababa. It has fourteen administrative units (kebeles). According to the town information desk office report of 2018 population census, the total population was 97,969 (44,300 males and 53,669 females) [23]. Among the total population 14,437 were youth females 15-24 years of old.

\section{Sampling and population}

The source population was all female youths who were from 15-24 years old found within fourteen kebeles (small administrative units) in Debre Birhan town. All youths who were living in the selected kebeles of DebreBirhan town were considered as the study population. All youth's from15-24 years that were available in the town during the study period were included; whereas youths who were physically and mentally ill at the time of data collection were excluded in the study. The sample size was determined by using single population proportion formula by considering the following assumptions: $60 \%$ the proportion of who heard about sexual trafficking of the previous study in Bahirdar [16], 95\% a confidence interval, 5\% marginal error, since the sampling procedure is multistage the design effect was taken as 1.5 and 5\% non-response .Based on these, the final sample size of the study was 582. Among the total of fourteen kebeles found in Debrebirhan town only six kebeles were selected by lottery method of simple random sampling technique. By using population proportional to size (kebele 2=123, kebele $4=126$, kebele $6=113$, kebele $8=92$, kebele $10=49$ and kebele12 $=69$ ) were the allocated number of households 'of the selected kebeles in which female youths were living. Therefore, the sample size for each household in which youth females were living was selected using systematic random sampling technique. The sampling frame was obtained CHIS, and then sampling interval $(\mathrm{K})$ was calculated by dividing the number of households with young female to the sample size. So that $\mathrm{k}=\mathrm{N} / \mathrm{n}=$ every 7 th household was visited until 582 youth females included. The first household was selected by lottery method from the sampling interval (K). If there was more than one young female in a household, lottery method was used to select one participant. If the selected youth female was not available at home at the time of visit, revisit for the second time was made to contact the selected young for interview.

\section{Study Variables}

Dependent variable

Awareness of sexual trafficking

Independent variable

1. Sociodemographic characteristics' of participants

Age

Marital

Father's educational status

Mother's educational status

Family size

Income

Occupation

2. Participant's socio-demographic status:-

Educational level

Marital status

Occupation 


\section{Access to mass-media}

Access to TV

Access to Radio

Access to social-media, fb, twitter and etc.

4. Education/Training on Gender Based Violence

Education by health care provider

Education by police

Education by teachers

Participation on clubs at schools

Peer-education programs

\section{Operational Definitions/term definitions}

Sexual trafficking: the recruitment, transportation, transfer, harboring, or receipt of persons, by

means of the threat or use of force or other forms of coercion, of abduction, of fraud, of deception, of the abuse of power or of a position of vulnerability" for the purposes of sexual exploitation and for economic and other personal gains.

Awareness of sexual trafficking: having information on sex trafficking if she reported that she had heard or read about sexual trafficking that a woman who had been taken to another place or foreign countries for the purposes of sexual exploitation to gain money or other personal gains. Based on total score, the level of awareness was categorized depending on mean value.

\section{Good awareness of sexual trafficking:}

Awareness index was constructed from the answers to eight questions (ever heard sexual trafficking, mediators of sexual trafficking, source of information on sexual trafficking). According to this awareness of sexual trafficking was considered as good awareness (score $>=8$ ).

\section{Poor awareness of sexual trafficking:}

Awareness index was constructed from the answers to eight questions (ever heard sexual trafficking, mediators of sexual trafficking, source of information on sexual trafficking). According to this awareness of sexual trafficking was considered as poor awareness $($ score $<=8)$.

\section{Data collection tool and procedure}

Structured interviewer administered questionnaire was used to elicit information about sex trafficking from the study participant. The questionnaire was taken from the previous study done in Bahirdar town [26].The questionnaire was first prepared English then translated to local language, Amharic language, to keep consistency. The questionnaire contained about socio-demographic characteristics of the young females, their parents and sexual trafficking awareness. Five health extension workers were recruited as data collectors and three BSC nurses as supervisors had given training for two days. Data collection was carried out every 7th household, by interviewing young females in six kebeles until the required sample size obtained. Pretest was conducted on 59 of female youths from non-selected kebeles and correction was made accordingly. The collected data was reviewed and checked for completeness before data entry; the incomplete data was discarded.

\section{Data processing and analysis}

The data were coded, cleaned and edited for its completeness, consistency and accuracy before analysis using Epidata version 3.1 and exported to SPSS version 24 for analysis. Descriptive statistics (frequency, mean, percentage and standard deviation) was calculated and result presented with table and charts. All Variables having $p$ value $<$ 0.25 in the Bivariate analysis were moved in to the multivariable logistic regression. The $95 \%$ confidence interval and variables having p-value $<0.05$ in the multivariate binary logistic regression model was considered as significantly associated with the dependent variable. Adjusted Odds Ratio with $95 \%$ confidence interval was used to see the strength of the association between dependent and independent variables

\section{RESULTS}

\section{Socio-demographic characteristics of youth females}

A total of 582 youth females participated in this study with response of 100 percent.

The mean age of youth females was $19.14+2.679$ years with $( \pm 7.96$ standard deviation $)$. Majority of participants' age group (58.1\%) was 15-19 years. Most of the youth females 517(88.8\%) had single marital status. According to this study, about $521(89.5 \%)$ and 522(89.7\%) participants were Orthodox by religion and Amhara by ethnicity respectively. The educational status of youth females revealed that, $216(37.1 \%)$ and 208(35.7\%) were have College and above and secondary educational status respectively. Four hundred forty one $(75.8 \%)$ of the participants' house had radio and $271(46.6 \%)$ of the participants house had television in their home. Regarding social media, $196(33.7 \%)$ of the youth females used face book. Two hundred thirty nine (41.1\%) of respondents lived with Parents and 393(67.5\%) of the respondents' job was schooling/student (see table1).

Socio-demographic characteristic of respondents' parents

Four hundred forty nine (77.1\%) participants' parents were married. About 517(88.8\%) of the respondents' parents' 
religion were Orthodox and 41(7\%) were Muslim. Two hundred sixty participants' fathers (44.7\%) and 214(36.8\%) participants' mothers were able to read and write. Concerning family size, 517(88.8\%) of youth females had greater or equal to four families in their household. Regarding to estimated monthly income of youth females parents', almost half of respondents 272(46.7\%) earned from 2001-3500 birr per month, 192(33\%) of respondents earned greater than or equal to 3501 birr and the rest $118(20.3 \%)$ of respondents earned less than or equal to 2000 birr regarding with parents job status, most respondents' 336(57.7\%) were civil servant (see table2).

\section{Awareness sexual trafficking among the youth female}

Regarding the source of information, about $56.6 \%$ and $56.0 \%$ of the youth females mentioned television, radio, respectively as sources of information. Brokers, friends and family were mentioned as mediators for sex trafficking by $85.5 \%, 30.5 \%$ and $14.9 \%$ of the youth females respectively. According to this study, about $70 \%$ of the respondents mentioned that they had heard of women being taken abroad for better work was become victim of sexual trafficking and $55.9 \%, 53.7 \%$ and $21.9 \%$ of the respondents mentioned radio, television and friends respectively as sources of information for it. Concerning about the cause of sexual trafficking, $53.3 \%, 32.7 \%$ and $29.0 \%$ of youth females mentioned poverty, unemployment and hoping for a better life elsewhere respectively as reasons for being trafficked. Regarding the vulnerability age, about $56 \%$ of the participants reported that they did not know vulnerable age for sexual trafficking whereas $24.3 \%$ of the participants reported that youth female's ages less than 25 years were vulnerable for sexual trafficking. About $72(24 \%)$ of the participants reported that they had been approached by someone else to assist them go abroad. One hundred eighty nine $(63 \%)$ of the respondents had good awareness of sexual trafficking. Of all youth females, about 300 (52\%) of respondents had awareness about sexual trafficking (see fig1).

\section{Factors Associated With Awareness of Sexual Trafficking}

In Bivariate logistic regression analysis, parent's religion, father's education, mother's education, parent's occupation, participant's age, participant's education, having television at home, using social media like, face book, current job of the respondents and getting training on gender issues were significantly associated with awareness of sexual trafficking. However, in multivariable binary logistic regression analysis, mothers' education status, parents 'occupation, current jobs of participant, having television in home and have taking training on gender issues were significantly associated with awareness of sexual trafficking with a p-value $<0.05$. According to this study, youth females whose parents' education status was elementary and secondary were 2.068 (AOR $=2.068,95 \%$ CI: $1.079-3.963)$ and $3.446(\mathrm{AOR}=3.446,95 \% \mathrm{CI}: 1.298$-9.154) times more likely to be aware about sexual trafficking respectively compared to those youth females whose parents' education status was illiterate. Youth females whose parents' occupation was Governmental workers were about 2.2(AOR=2.2, 95\% CI: 1.02-4.747) times more likely to be aware about sexual trafficking compared to those youth females whose parents' occupation was farming. Youth females who had governmental work were about 6.203 (AOR $=6.203,95 \%$ CI: $1.099-35.005$ ) times more likely to be aware about sexual trafficking compared to those youth females were jobless. Based on this study, youth females who had television at home were about 2.083 (AOR $=2.083,95 \% \mathrm{CI}$ : 1.305-3.326) times more likely to be aware about sexual trafficking compared to their counterparts.

Youth trained on gender issues were 3.887 (AOR $=3.887,95 \% \mathrm{CI}: 2.591-5.832)$ times more likely to be aware about sexual trafficking compared to those youth females who did not take the training (see table 4).

\section{DISCUSSION}

The study was aimed to assess awareness of sexual trafficking and associated factors among youth females. It was supposed that, this study provided important information and created overall image on awareness of sex trafficking and associated factors among youth females in Debre Birhan town of North Shewa zone. In this study, 52\% of respondents had awareness of sexual trafficking which was lower than studies conducted in Nepal, Nigeria and Ethiopia (Bahir Dar) showed that $76 \%, 86.1 \%$ and $60 \%$ of the respondents had awareness of sexual trafficking, respectively [16-18]. Similarly, a cross sectional study conducted in Nigeria showed that $97.4 \%$ of the women reported that they had heard of women being taken abroad for commercial sex work [19]. This discrepancy was due to the implementation of sexual trafficking prevention interventions, as well as cross-cultural variation.

Regarding the source of information, the youth females stated television (56.6\%), radio (56.0\%) and friends $(22.2 \%)$ as sources of information in this study whereas in the Bahirdar study the youth females mentioned television (64\%), friends (46\%) and radio (37\%) as sources of information [26]. On the other hand, the study done in Nepal, $94.6 \%, 49.5 \%, 36 \%, 24.3 \%$, and $15.3 \%$ of the respondents mentioned media (i.e., radio or television), friends, family/relatives, schools and NGOs/health professionals as sources of information respectively [17]. The possible reason might be due to the presence of difference source of information among different area. Brokers and friends were mentioned as mediators for sex trafficking by $85.5 \%$ and $30.5 \%$ of the study participants; individually whereas in a study done in Bahirdar,Ethiopia friends and brokers were mentioned by $87 \%$ and $74 \%$ of the respondents, respectively as mediators for sex trafficking [16]. Similarly, the study carried out in Nepal, relatives $(51.4 \%)$ and friends $(34.2 \%)$ were mentioned as mediators for sexual trafficking [17]. The above findings were inconsistent with the studies done in Nigeria and South Africa [18,20].This might be due to the Knowledge 
difference about the mediators and existence of different mediators in different areas.

Concerning about the cause of sexual trafficking, $53.3 \%, 32.7 \%$ and $29.0 \%$ of the youth females mentioned poverty, unemployment and hoping for a better life elsewhere, respectively as reasons for being trafficked. Similarly, the study done in Bahirdar city, $45 \%, 50 \%$ and $72 \%$ of the study participants mentioned poverty, unemployment and hoping for a better life elsewhere, one by one as reasons for sex trafficking [16]. These findings were not in line with those reported in studies from Nigeria, South Asia, and South Africa [18, 21, 22].On the other hand, the study done in Nepal showed that $62.2 \%, 58.6 \%, 56.8 \%$, and $25.2 \%$ of the respondents mentioned poverty, lack of awareness, interest on big money, and illiteracy correspondingly as reasons for being trafficked [17]. The possible explanation was due to having knowledge difference on the causes of sexual trafficking and presence of different causes in different countries.

Regarding to the vulnerability age group, about $24.3 \%$ of the participants reported that youth female's aged less than 25 years were vulnerable for sexual trafficking which was lower than the studies done in Nepal (48.6\%),Ethiopia(Bahirdar) (71.4\%) and South Asia (72\%) [16, 17,21].The discrepancy was due to gap of knowledge on vulnerable age group for sexual trafficking among youth females. In this study, about $24 \%$ of youth females had been approached by someone to assist them to go abroad which was lower than the studies done in Bahirdar, Ethiopia (25\%) and Benin City in southern Nigeria (31.9\%) [16,19]. This discrepancy may be due to the extent of the problem and sexual trafficking promotion activities.

This study also revealed that youth females whose mothers' education status was elementary and secondary were about 2.068(AOR=2.068, 95\% CI: 1.079-3.963) and 3.446(AOR=3.446, 95\% CI: $1.298-9.154)$ times more likely to be aware about sexual trafficking respectively compared to those youth females whose parents' education status was illiterate. However, study done in Nepal showed that the educational status of mother was not associated with awareness of sexual trafficking. This might be due to the fact that educated mothers, simply due to their tied up life style, might not have intimate approach with their daughters which might in turn influence the awareness of their daughters' regarding about sexual trafficking.

Regarding the parents' occupation, the study revealed that youth females whose parents' occupation was Governmental employment were about $2.2(\mathrm{AOR}=2.2,95 \% \mathrm{CI}: 1.02-4.747)$ times more likely to be aware about sexual trafficking compared to those youth females whose parents' occupation was farming. Similarly, the study done in Nepal showed that youth females' family's primary occupation was Governmental employment were 3.89(1.58-9.58) times more

likely to be aware about sex trafficking than those whose family's primary occupation was agriculture (farming) [17]. The reason might be due to the fact that governmental workers might have high access of social media and mass media than farmer as source of information for sexual trafficking. The reason might be due to the Government workers might have different life status and awareness about sexual trafficking from country to the country. In this study, youth females who had governmental worker at current situation were about 6.203(AOR = $6.203,95 \%$ CI: $1.099-35.005)$ times more likely to be aware about sexual trafficking compared to those youth females who had doing daily wages. This finding was not supported by the findings of Bahir Dar town study and Nepal study $[16,17]$. This might be due to the fact that youth females might have different work from place to place and this might affect the awareness of youth females about sexual trafficking. According to this study, youth females who had television at home were about $2.083(\mathrm{AOR}=2.083,95 \% \mathrm{CI}: 1.305-3.326)$ times more likely to be aware about sexual trafficking compared to their counterparts. In line with this study, the study done in Bahir Dar town revealed that youth girls who had television at home were about $2.19(\mathrm{AOR}=2.19,95 \% \mathrm{CI}$ : 1.31-3.67) times more likely to be aware about sexual trafficking compared to their counterparts. However, the study done in Nepal revealed that respondents who had radio or television at home were about 6.67(3.99-9.54) times more likely to be aware about sexual trafficking compared to those who did not[17]. This might be due to using radio or television together as one variable rather than using separately for each radio and television in Nepal study. Based on this study, youth females trained on gender issues were 3.887(AOR $=3.887,95 \%$ CI: 2.591-5.832) times more likely to be aware about sexual trafficking compared to those youth females who did not take the training. This finding was in agreement with the study conducted in Bahirdar town Ethiopian (AOR = 3. 59, 95\% CI: 2.11-6.10) [16].This was due to the positive influence of having taken training on gender issues to avert sexual trafficking among female youths.

\section{Conclusion}

Generally the finding of the study on awareness of sexual trafficking among youth females in Debre Berhan town was low. Mother's educational status, parent occupation of government worker, presence of television at home, current job of the study participants and taking training on gender issues were found statistically significant association with low awareness about sexual trafficking among youth females. The local authority of mothers, youth and females affairs have focus on educational and information accessibilities about sexual trafficking to youth females and their parents as well as the community.

Limitations: Since the study design was cross-sectional there was casual-effect relationship drawback. As to the 
searching of the researchers as possible there was a scarcity of related literatures' to incorporate with this study. Abbreviations

$\mathrm{AOR}=$ Adjusted Odd Ratio, $\mathrm{CHIS}=$ Community Health Information System, $\mathrm{CI}=$ Confidence Interval, $\mathrm{COR}=\mathrm{Crude}$ Odd Ratio, ILO=International Labor Organization, US=United States

\section{Acknowledgement}

We would like to thank Debre Berhan University, College of Health Sciences, and the Department of Public Health. Our deepest and special thanks go to Debre Berhan town Administrator office for writing letters of permission to each kebele. We would also like to say thank you very much for their assistance of data collectors, supervisors and study participants.

Authors' contribution

NA had involved in the conception, design, analysis, result and manuscript writing. AE had involved interpretation, report and manuscript writing. Both authors read and approved the final manuscript.

\section{Funding}

This work was funded by Debre Berhan University.

\section{Availability of Data and materials}

The data that support the findings of this study are available but some restrictions may apply to the availability of these data as there are some sensitive issues. However, data are available from the corresponding authors upon reasonable request.

\section{Ethical Consideration}

Ethical clearance was obtained from Debre Birhan University College of health science, Official letters and permission was given from Debre Birhan town and selected kebeles. Informed consent was found from a respondent from each study participant. Confidentiality was maintained by omitting their name and personal identification. The participant had right to withdraw themselves from the study at any time.

\section{Consent for publication}

Not applicable.

Competing interests

The authors declared that they have no competing interests.

\section{Authors' information}

- Natnael Atnafu is a Lecturer in the Department of Midwifery, College of Health Science and Medicine, Wolaita Sodo University, Wolaita Sodo, Ethiopia.

- Awoke Elefachew is a lecturer in the Department of Nursing, Colleague of health science, DebreBerhan Health Science Colleague, DebreBerhan, Ethiopia

\section{References}

1. International Organization for Migration (IOM): Assessment of Trafficking in Women and Children in and from Ethiopia. Addis Ababa, Ethiopia: IOM; 2010. Available at URL:[http://www.africanchildinfo.net/index2.php?option=com_sobi2\&sobi2Task=dd_do wnload \& fid $=604 \&$ format $=$ html\&Itemid

2. United Nations Office of Drugs and Crime: Protocol to Prevent, Suppress, and Punish Trafficking in Person, Especially Women and Children, Supplementing the United Nations Convention Against Transnational Organized Crime. New York (NY): United Nations Office on Drugs and crime. Available at URL:http://www.uncjin.org/Documents/Conventions/dcatoc/final_documents_2/conventi on_\%20traff_eng.pdf]

3. United Nations Office of Drugs and Crime: Trafficking In Persons: Global Patterns. Vienna, Austria: United Nations Office on Drugs and Crime;

4. International Labour Organization (ILO): ILO Global Estimate Of Forced Labour: Results And Methodology. Geneva: ILO; 2012. Available from at URL: [http://apflnet.ilo.org/resources/ilo-global-estimate-of-forcedlabour-2012-results-andmethodology/at_download/file]

5. United Nations Crime and Justice Information network (UNCIJIN), Annual Report on human trafficking crimes; 2010

6. U.S. Department of State. "Ethiopia," in Country Reports on Human Rights Practices- 2013. Washington, DC; February 27, 2014;http://www.state.gov/documents/organization/22032

7. United State Department of State, Trafficking in persons Report -Ethiopia;2012 http://www.state .gov/documents /organization /192595-pdf.

8. International Labour Organization. Trafficking in persons overseas for labour purposes. The case of Ethiopian domestic workers. ILO country office, AddisAbaba:Ethiopia;2013.

9. Ethiopian women face new threat of human trafficking as economic gains slow to trickle down; 2016(http://thepeninsulaqatar.com/article/26/11/2016/Ethiopian-women-face-newthreat-of-humantrafficking-as-economic-gains-slow-to-trickle-down) 
10. Zimmerman C, Hossain M, Watts C: Human trafficking and health: a conceptual model to inform policy, intervention and research. SocSci Med 2011, 73:327-335.

11. Hossain M, Zimmerman C, Abas M, Light M, Watts C: The relationship of trauma to mental disorders among trafficked and sexually exploited girls and women. Am J Public Health 2010, 100(12):2442-2449,

12. Beydoun, Khaled.The Trafficking of Ethiopian Domestic Workers into Lebanon: Navigating through a Novel Passage of the International Maid Trade. Berkeley Journal of International Law, 2006 :Vol. 24 (3).

13. Mesfin, D. The Challenges and prospects of female labour migration to the Arab Middle East: A Case study of women returnees in the town of Girana, North Wollo, Ethiopia;2011.A Thesis submitted to the University of Bergen, Faculty of Psychology (Unpublished Masters Thesis)

14. Asefach HaileselassieAn Investigation in to the experiences of Female victims of Trafficking in Ethiopia. University of South Africa: Cape Town, South Africa;2012.

15. Elias Ashine. Trafficking of Ethiopian women and girls to the Middle East. Hungary: Central European university;2013.

16. Azage M, Abeje G, Mekonnen A. Sex trafficking awareness and associated factors among youth females in Bahir Dar town, North-West Ethiopia: a community based study. BMC women's health. 2014; 14:85-687414-85

17. Shrestha R, Karki P, Suwal A and Copenhaver M. Sex Trafficking Related Knowledge, Awareness, and Attitudes among Adolescent Female Students in Nepal: A Cross Sectional Study. PLoS ONE July 15, 2015;10(7):

18. Omorodion FI: Vulnerability of Nigerian secondary school to human sex trafficking in Nigeria. Afr J Reprod Health 2009, 13(2):33-48.

19. Okonofua FE, Ogbomwan SM, Alutu AN, Kufre O, Eghosa A: Knowledge, attitudes and experiences of sex trafficking by young women in Benin City, South-South Nigeria. SocSci Med 2004, 59:1315-1327

20. Woolman S, Bishop M: State as pimp: sexual slavery in South Africa. Dev South Afr 2006,23(3):385-400

21. Huda S. Sex trafficking in South Asia. World Report on Women's Health 2006; Women'sRight to Health and the Millenium Development Goals; Promoting Partnerships to ImproveAccess. 2006; 94(3):374- 8

22. Ghimire D, editor Prevention, Care, Rehabilitation and Reintegration of Rescued Girls:ABC's Experience. Technical Consultative Meeting on Anti-trafficking Programmes South Asia; 2001

23. Debrebirhan town Administration Health Office: Annual report of Debrebirhan town Administration Health Office. Debrebirhan town, Amhara Region, Ethiopia: 2018. 
Table1: Socio-demographic characteristics of youth females in DebreBerhan town, North Shewa, Ethiopia, 2019 ( $\mathrm{N}=582)$

\begin{tabular}{|c|c|c|c|}
\hline \multirow[t]{2}{*}{ Variables } & \multirow[t]{2}{*}{ Frequency $(\%)$} & \multicolumn{2}{|c|}{$\begin{array}{l}\text { Awareness of sexual } \\
\text { trafficking }\end{array}$} \\
\hline & & Yes & no \\
\hline \multicolumn{4}{|l|}{ Age } \\
\hline $15-19$ & $338(58.1)$ & 159 & 179 \\
\hline $20-24$ & $244(41.9)$ & 141 & 103 \\
\hline \multicolumn{4}{|l|}{ Marital status } \\
\hline Single & $517(88.8)$ & 265 & 252 \\
\hline Married & $65(11.2)$ & 35 & 30 \\
\hline \multicolumn{4}{|l|}{ Religion } \\
\hline Orthodox & $521(89.5)$ & 259 & 262 \\
\hline Muslim & $42(7.2)$ & 33 & 9 \\
\hline Protestant & $19(2.1))$ & 7 & 12 \\
\hline Catholic & $7(1.2)$ & 1 & 6 \\
\hline \multicolumn{4}{|l|}{ Ethnic } \\
\hline Amhara & $522(89.7)$ & 263 & 259 \\
\hline Oromo & $31(5.3)$ & 16 & 9 \\
\hline Tigre & $9(1.5)$ & 2 & 12 \\
\hline Guragie & $20(3.4)$ & 14 & 6 \\
\hline \multicolumn{4}{|c|}{ Respondent's educational status } \\
\hline Illiterate & $9(1.5)$ & 6 & 3 \\
\hline Read and write & $35(6)$ & 7 & 28 \\
\hline Elementary & $114(19.6)$ & 52 & 62 \\
\hline Secondary & $208(35.7)$ & 109 & 99 \\
\hline Collage and above & $216(37.1)$ & 126 & 90 \\
\hline \multicolumn{4}{|l|}{ Presence of radio at home } \\
\hline Yes & $441(75.8)$ & 227 & 214 \\
\hline No & $141(24.2)$ & 73 & 68 \\
\hline \multicolumn{4}{|l|}{ Presence of TV at home } \\
\hline Yes & $271(46.6)$ & 172 & 99 \\
\hline No & $311(53.4)$ & 128 & 183 \\
\hline \multicolumn{4}{|c|}{ Using social media ,like face book } \\
\hline Yes & $196(33.7)$ & 129 & 67 \\
\hline No & $386(66.3)$ & 171 & 215 \\
\hline \multicolumn{4}{|c|}{ With whom are you living now } \\
\hline Parents & $239(41.1)$ & 2 & \\
\hline Boy friend/fiancé/husband & $96(16.5)$ & 25 & 22 \\
\hline Mother & $37(6.4)$ & 207 & 186 \\
\hline Father & $6(1)$ & 22 & 15 \\
\hline Step parents & 11(1.9) & 9 & 12 \\
\hline Relatives & $69(11.9)$ & 16 & 5 \\
\hline Alone & $124(21.3)$ & 21 & 42 \\
\hline \multicolumn{4}{|c|}{ Taking education or training about gender issue } \\
\hline Yes & $352(60.5)$ & 226 & 126 \\
\hline
\end{tabular}


Table2: Socio-demographic characteristics of youth females' parents in Debrebirhan town, North Shewa, Ethiopia $2019(\mathrm{~N}=582)$

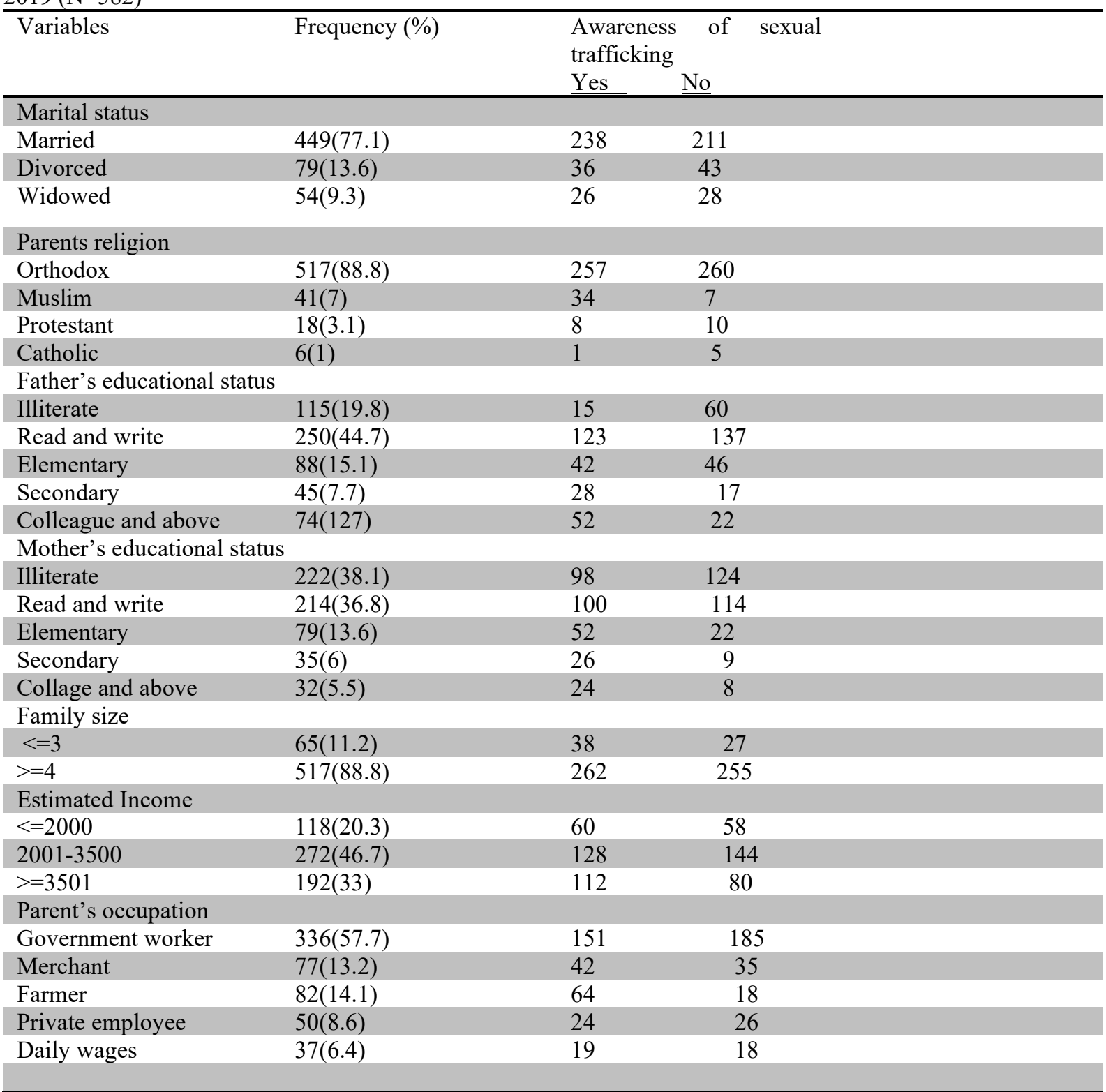


Table 3: Factors associated with awareness of sexual trafficking among female youths in Debre Berhan town, North shewa, Ethiopia, 2019(N=582)

\begin{tabular}{|c|c|c|c|c|}
\hline \multirow[t]{2}{*}{ Variables } & \multicolumn{2}{|c|}{$\begin{array}{l}\text { Awareness of } \\
\text { sexual trafficking }\end{array}$} & \multirow[b]{2}{*}{ COR } & \multirow[b]{2}{*}{ AOR } \\
\hline & Yes & No & & \\
\hline \multicolumn{5}{|l|}{$\overline{\text { Age }}$} \\
\hline $15-19$ & 159 & 179 & 1 & 1 \\
\hline $20-24$ & 141 & 103 & $1.541(1.106-2.150)^{*}$ & $1.560(0.993-2.451)$ \\
\hline \multicolumn{5}{|l|}{ Parent's religion } \\
\hline Orthodox & 257 & 260 & 1 & 1 \\
\hline Muslim & 34 & 7 & $4.914(1.139-11.28)^{*}$ & $3.57(0.403-9.083)$ \\
\hline Protestant & 8 & 10 & $0.809(0.314-2.083)$ & $0.391(0.128-1.213)$ \\
\hline Catholic & 1 & 5 & $0.202(0.023-1.744)$ & $0.091(0.008-1.041)$ \\
\hline \multicolumn{5}{|c|}{ Father's educational status } \\
\hline Illiterate & 55 & 60 & 1 & 1 \\
\hline Read and write & 123 & 137 & $0.979(0.631-1.520)$ & $0.798(0.435-1.464)$ \\
\hline Elementary & 42 & 17 & $2.695(0.571-1.736)$ & $0.457(0.199-1.048)$ \\
\hline Secondary & 28 & 46 & $1 .(0.888-3.636)$ & $0.737(0.261-2.077)$ \\
\hline Collage and above & 52 & 22 & $\left.2.579(1.389-4.785)\right|^{*}$ & $0.330(0.103-1.060)$ \\
\hline \multicolumn{5}{|c|}{ Mother's educational status } \\
\hline Illiterate & 98 & 124 & 1 & 1 \\
\hline Read and write & 100 & 114 & $1.11(0.761-1.618)$ & $0.998(0.645-1.546)$ \\
\hline Elementary & 52 & 27 & $2.437(1.427-4.161)^{*}$ & $2.068(1.079-3.963) * *$ \\
\hline Secondary & 26 & 9 & $3.655(1.638-8.159)^{*}$ & $3.446(1.298-9.154)^{* *}$ \\
\hline Collagand above & 24 & 8 & $3.796(1.634-8.818)^{*}$ & $1.800(0.622-5.215)$ \\
\hline \multicolumn{5}{|l|}{ Parent's occupation } \\
\hline Farmer & 18 & 64 & 1 & 1 \\
\hline Merchant & 42 & 35 & $4.267(0.894-2.418)$ & $0.626(0.322-1.215)$ \\
\hline Gov’t worker & 151 & 185 & $2.902(2.475-7.667)^{*}$ & $2.200(1.020-4.747) * *$ \\
\hline Private worker & 24 & 26 & $3.282(0.624-2.05)$ & $0.788\left(0.380 \_1.635\right)$ \\
\hline Daily wages & 19 & 18 & $3.753(0.655-2.552)$ & $0.863(0.381-1.951)$ \\
\hline \multicolumn{5}{|c|}{ Educational status of participants } \\
\hline Illiterate & 6 & 3 & 1 & \\
\hline Read and write & 7 & 28 & $0.125(0.025-0.628)^{*}$ & $5.019(0.992-25.382)$ \\
\hline Elementary & 52 & 62 & $0.419(0.106-1.760)$ & $0.197(0.069-1.564)$ \\
\hline Secondary & 109 & 99 & $0.551(0.134-2.260)$ & $0.911(0.507-1.637)$ \\
\hline Diploma and above & 126 & 90 & $0.700(0.171-2.873)$ & $0.787(0.481-1.285)$ \\
\hline \multicolumn{5}{|c|}{ Presence of TV at home } \\
\hline Yes & 172 & 99 & $2.484(1.777-3.470)^{*}$ & $2.083(1.305-3.326) * *$ \\
\hline No & 128 & 183 & 1 & 1 \\
\hline \multicolumn{5}{|c|}{ social media ,like face book } \\
\hline Yes & 129 & 67 & $2.421(1.694-3.460)^{*}$ & $1.277(0.804-2.030)$ \\
\hline No & 171 & 215 & 1 & 1 \\
\hline \multicolumn{5}{|c|}{ Current job of respondent } \\
\hline Jobless & 25 & 22 & $4.338(1,046-4.94)^{*}$ & $1.564(0.628-3.897)$ \\
\hline Student & 207 & 186 & $4.249(1.271-3.897)^{*}$ & $1.498(0.736-3.050)$ \\
\hline Merchant & 22 & 25 & $3.360(1.267-6.79)^{*}$ & $1.703(0.630-4.603)$ \\
\hline Hair dressing & 9 & 12 & $2.864(0.546-4.121)$ & $0.419(0.117-1.507)$ \\
\hline Gov't worker & 16 & 5 & $12.218(2.224-33.78)^{*}$ & $6.203(1.099-3.005) * *$ \\
\hline Daily wages & 11 & 42 & 1 & 1 \\
\hline \multicolumn{5}{|c|}{ Taking training or education on gender issue } \\
\hline Yes & 226 & 126 & $3.781(2.659-5.377)$ & $3.887(2.591-5.832)^{* *}$ \\
\hline No & 74 & 156 & 1 & 1 \\
\hline
\end{tabular}




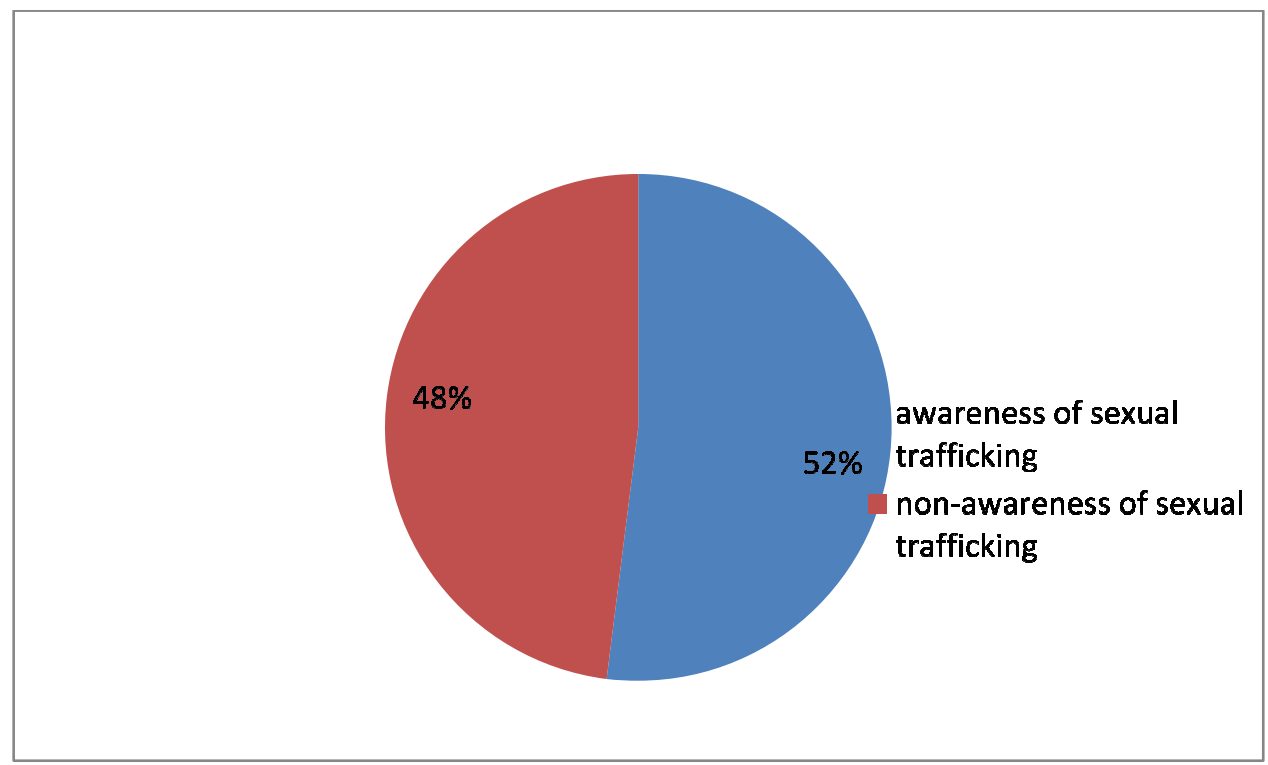

Figure1. Level of awareness of sexual trafficking among youth females in Debre Berhan town, Ethiopia 2019 